\title{
Representações do intelectual engajado na obra de Erico Veríssimo
}

\author{
Donizeth Aparecido dos Santos ${ }^{1}$
}

Resumo: Segundo Erico Verissimo (1976), um dos propósitos do romance O senhor embaixador (1965) era mexer com um problema que sempre o preocupou: o engajamento do intelectual em uma revolução de caráter violento. Se recordarmos as suas obras anteriores, essa preocupação já se encontra em $O$ arquipélago (1962), última parte da trilogia O tempo e o vento, na pessoa do escritor Floriano Cambará. Dessa forma, o intelectual Pablo Ortega representa uma evolução do pensamento do escritor sobre a questão do engajamento ou não do intelectual, pois é a partir dele que surge na obra de Erico a figura do homem de pensamento que se torna um homem de ação. Nesse sentido, este trabalho apresenta uma análise do posicionamento sociopolítico das personagens Floriano Cambará e Pablo Ortega à luz das teorizações de Jean-Paul Sartre (1994) e Edward Said (2005) sobre a função social dos intelectuais.

Palavras-chave: Romance político, engajamento, intelectual

1 Introdução

Como bem observou Antonio Candido (1972, p.44), na maioria dos livros de Erico Verissimo há personagens com status de intelectual, com força e condições de debater os problemas sócio-politicos que os circundam. Assim temos Noel e Fernanda em Caminhos Cruzados e Um lugar ao sol, Tônio Santiago em $O$ resto é silêncio, Vasco e Clarissa em Música ao longe e Saga, Floriano Cambará e Roque Bandeira em $O$ tempo e o vento, Leonardo Gris e Pablo Ortega em $O$ senhor embaixador, e o professor Martim Francisco Terra em Incidente em Antares. Todos eles, na condição de intelectuais humanistas, são contra qualquer tipo de violência ao ser humano, assim como o próprio autor.

No entanto, a questão do engajamento do intelectual em um conflito armado, violento, foi sempre uma preocupação do escritor, como ele mesmo frisou no segundo volume de Solo de Clarineta (1976), ao falar do processo de criação de $O$ senhor embaixador (1965). Segundo ele, "o romance se prestaria também para mexer com um problema que sempre me preocupou: a participação do intelectual na política militante e, mais especificamente, numa revolução de caráter violento" (1976, p.62).

Ora, sabemos que Erico Verissimo já tinha feito isso em 1940, quando escreveu Saga, colocando Vasco na Guerra Civil Espanhola, lutando contra as forças de Franco. Sabemos também que essa obra foi quase um desastre na carreira do escritor, desagradando a crítica em geral e, principalmente, ele mesmo. Politicamente o livro desagradou tanto direitistas quanto esquerdistas. Por fim, o escritor acabou por renegar esse romance, considerando-o uma espécie de "ovelha negra" no conjunto de sua obra literária. Talvez por isso tenha resolvido rediscutir a questão do engajamento do intelectual num conflito armado, fazendo-a, dessa vez, de forma gradativa e coerente.

Se olharmos o projeto literário de Erico Verissimo e o modo como ele passa do romance histórico para o romance político a partir de $O$ tempo o vento, podemos identificar o retorno dessa preocupação na personagem Floriano Cambará em $O$ arquipélago, terceira parte da trilogia. Floriano, a nosso ver, é uma personagem que antecede o engajado Pablo Ortega de $O$ senhor embaixador, e assim, este último representa uma evolução do pensamento do escritor. Nesse sentido, faremos, neste trabalho, uma análise do posicionamento político-ideológico dessas duas personagens, levando em consideração as definições do intelectual e sua função social de Jean-Paul Sartre e Edward Said.

\section{Algumas considerações sobre o intelectual}

O intelectual, essa figura polêmica por essência, surgiu no final do século XIX e ainda hoje suscita muitas discussões sobre a sua função social. Exemplo disso foi a recente realização aqui no Brasil do ciclo de conferências "O silêncio dos intelectuais", que abordou a opção de muitos deles de não se manifestar publicamente perante os problemas contemporâneos.

\footnotetext{
${ }^{1}$ Universidade de São Paulo
} 
O termo intelectual surgiu na França, em 1894, por ocasião do "caso Dreyfus". Na época, o capitão das forças armadas francesas Alfred Dreyfus, de origem judia, foi acusado injustamente de traição por atos de espionagem em favor da Alemanha. A condenação injusta por alta traição desencadeou uma série de protestos envolvendo pessoas com diferentes tendências políticas e culminou na absolvição completa de Dreyfus em 1906. A maior dessas manifestações foi o artigo J'accuse, do escritor Emile Zola. Segundo Moacyr Scliar

diante dessa maré de intolerância, a esquerda e os liberais se deram conta de que não poderiam ficar calados e inermes. Alguém precisava funcionar como intérprete da realidade sócio-política e cultural, como voz da consciência. Surgia assim o intelectual. A palavra, aparentemente não existia antes do caso Dreyfus. Sua criação é atribuída ora Clemenau ora ao direitista Maurice Barrès, que a usou para referir-se ironicamente aos signatários de um manifesto lançado em defesa de Dreyfus. (SCLIAR, 2006, p.6)

Desse modo, conforme, Jean-Paul Sartre (1994), o termo "intelectual" surge com uma conotação pejorativa para designar alguém que se mete no que não é da sua conta, ou seja, alguém que, atingindo uma notoriedade em algum campo do saber, como a literatura, a filosofia e a ciência, abusava desse mérito adquirido, saindo de seu domínio e entrando em outros, e assim criticava sociedade e os poderes estabelecidos em nome de uma concepção global e dogmática do homem, que segundo ele pode ser vaga ou precisa, moralista ou marxista.

Corroborando o pensamento de Sartre, Michael Foucault, em uma entrevista ao jornal Le Monde, esboçou um retrato do que seria a figura do intelectual: “... é o culpado. Culpado um pouco de tudo: de falar, de silenciar, de não fazer nada, de meter-se em tudo... em suma, o intelectual é a matéria-prima a julgar, a condenar, a excluir..." (apud FUSINATO, 2004, p.2)

Sartre (1994, p.24-26) define o intelectual moderno como um "homem-contradição". Primeiro porque, sendo humanista desde a infância, acreditou que todos os homens eram iguais, e quando toma consciência de ser um sujeito detentor de um saber conquistado por herança (filho de funcionário alto salariado ou profissional liberal) ou através de um sistema de seleção complexo e injusto se for filho de operário, que eliminou a grande maioria de seus companheiros, vê em si mesmo a prova da desigualdade das condições humanas. Assim, para Sartre, esse privilégio injusto está em total contradição com o seu caráter humanista, e para renunciar a esse privilégio teria que se anular, solução que contradiz o instinto de vida profundamente enraizado tanto no intelectual quanto na maioria dos homens.

Desse modo, ainda de acordo com Sartre (Ibid, p.30-31), o intelectual é o homem que se conscientiza da oposição que há, em si mesmo e na sociedade, entre a verdade prática e a ideologia dominante, e essa conscientização põe a descoberto as contradições fundamentais da sociedade, ou seja, dos conflitos de classe no seio de classe dominante: um conflito orgânico entre a verdade que ela reivindica para seu empreendimento e os mitos, valores e tradições que ela mantém e que quer transmitir às outras classes para garantir sua hegemonia.

Para o filósofo italiano Antonio Gramsci (1982, p.201), todos os homens são intelectuais, embora nem todos desempenhem essa função na sociedade a que pertencem. Assim, ele divide em dois grupos aqueles que desempenham uma função intelectual: os intelectuais tradicionais e os intelectuais orgânicos. No primeiro grupo estariam professores, clérigos e administradores, que na visão de Gramsci, sempre estavam a fazer as mesmas coisas; e no segundo, o técnico industrial, o especialista em economia política, os organizadores de uma nova cultura, enfim, pessoas usadas na organização de interesses, conquista de poder e controle por classes ou empresas.

Edward Said, um dos mais importantes intelectuais do final do século XX, analisa a diferenciação dos dois grupos concebidos por Gramsci:

Gramsci acreditava que os intelectuais orgânicos estão ativamente envolvidos na sociedade; isto é, eles lutam constantemente para mudar mentalidades e expandir mercados; ao contrario dos professores e dos clérigos, que parecem permanecer mais ou menos no mesmo lugar, realizando o mesmo tipo de trabalho ano após ano, os intelectuais orgânicos estão sempre em movimento, tentando fazer negócios. (SAID, 2005, p.20)

Em um quase extremo, Said também analisa a definição de intelectuais de Julien Benda, para quem estes eram "um grupo minúsculo de reis-filósofos superdotados e com grande sentido moral, que constituem a consciência da humanidade" (Ibid., p.20), cujos exemplos de verdadeiros intelectuais mencionados por ele são Jesus Cristo e Sócrates:

De acordo com a definição de Benda, os verdadeiros intelectuais devem correr o risco de ser queimados na fogueira, crucificados ou condenados ao ostracismo. São personagens simbólicos, marcados por sua distância obstinada em relação a problemas práticos. Por isso, não podem ser numerosos, nem desenvolver-se de modo rotineiro. Tem de ser personalidade poderosa e, sobretudo, têm de estar num estado de quase permanente oposição ao status quo. (Ibid., p.22).

Organon, Porto Alegre, nº 47, julho-dezembro, 2009, p.147 - 161 
Para o próprio Edward Said (Ibid), o intelectual é um outsider, um perturbador do status quo, ou seja, não é nem um pacificador nem um criador de consenso: "alguém que empenha todo o seu ser no senso crítico, na recusa em aceitar fórmulas fáceis ou clichês prontos, ou conformações afáveis, sempre tão conciliadoras sobre o que os poderosos ou convencionais têm a dizer e sobre o que fazem." (Ibid., p.3536)

Quanto às funções (ou tarefas) do intelectual na sociedade, Said acredita que eles residem no esforço em derrubar os estereótipos e as categorias redutoras que tanto limitam o pensamento humano, em promover a liberdade humana e o conhecimento, e buscar uma relativa independência em face das pressões a que está sujeito, pois a liberdade de opinião e de expressão é o principal bastião do intelectual, e também encontrar espaço para enfrentar e retrucar a autoridade e o poder, porque, segundo ele, a subserviência inquestionável à autoridade é uma das maiores ameaças a uma vida intelectual ativa, baseada em princípios de justiça e equidade.

Já para Jean-Paul Sartre (Op. cit., p.53), a função do intelectual é viver sua contradição por todos e vencê-la por todos através do radicalismo, ou seja, pelo confronto da verdade à ilusão e à mentira. Assim, a sua contradição o transforma no guardião da democracia, levando-o a contestar a abstração dos direitos da democracia burguesa com a intenção de "completá-los com os direitos concretos da democracia socialista, conservando em toda democracia a verdade funcional da liberdade".

3 Representações do intelectual engajado na obra de Erico Verissimo

Floriano Cambará, filho do segundo Rodrigo Cambará, é um intelectual em atrito consigo mesmo, com a família e com o mundo à sua volta. Entre os problemas que enfrenta estão a sua crise de identidade, pois se sente um completo desenraizado em relação à sua terra, a sua postura apolítica, rejeitando qualquer envolvimento partidário ou ideológico; o problema de relacionamento com pai que vem desde a infância; a constante busca do seu papel social como romancista, o horror a violência num momento em que esta assola o mundo, a eterna procura pela liberdade que o transforma num prisioneiro dela; e o caso mal resolvido com Silvia, esposa do seu irmão Jango. Todos esses dilemas se arrastam até o último episodio de $O$ arquipélago, denominado a "Encruzilhada", onde Floriano terá que resolvê-los e decidir por qual caminho deverá trilhar. Maria da Glória Bordini comenta a aflição de Floriano perante a sua própria insubstancialidade nesse episódio:

Em "Encruzilhada", o pentaneto de Pedro e Ana se apresenta asfixiado pela carga da história intelectual e estética européia, à qual ele se filia como romancista, e que lhe granjeia a estranheza da sua gente e o pouco caso de seus críticos. Floriano percebe que existe um abismo entre o meio cultural a que pertence e a arte que pratica, cabendo-lhe, no romance, encontrar a relação possível entre a forma do romance, produto burguês importado, e o modo de vida dos gaúchos, mestiços em que as tradições dos indígenas, espanhóis e portugueses se entrecruzam e se chocam. (BORDINI, 1995, p.246)

Floriano Cambará, que vive no contexto histórico-político-social do período da segunda guerra mundial, é um verdadeiro "homem-contradição" no sentido que Jean-Paul Sartre (1994) definiu o intelectual. Sendo filho de um estancieiro gaúcho, representante da elite rio-grandense que se torna um figurão do governo Getúlio Vargas, ele tem a oportunidade, que é negada a muitos milhões de pessoas pela desigualdade social, de se formar em Direito em Porto Alegre, viver folgadamente às custas do pai no Rio de Janeiro, e até (por intermédio do pai) lecionar Literatura Brasileira na Universidade de Berkely na Califórnia. Assim, o saber que ele possui, visto pela ótica de Sartre, é um privilégio injusto que está em total contradição com o seu humanismo, e assim ele é a prova concreta da desigualdade entre os homens.

Nesse sentido, Antonio Candido (Op.cit., p.45) observa que o "Caderno de pauta simples", um miniepisódio que aparece nos intervalos dos dois episódios-chaves da narrativa em $O$ arquipélago (1961) e que funciona na estrutura do romance como um diário íntimo e literário de Floriano Cambará, é uma espécie de consciência dele e do grupo social a que pertence, e ali encontra-se uma das mais completas expressões que o sentimento de culpa do intelectual não-participante encontrou na obra de Erico. Candido cita como exemplo desse sentimento de culpa o trecho em que Floriano se acusa por ter ficado tomando sol em Copacabana ao lado da namorada, enquanto a miséria se alastrava pelo Rio de Janeiro e o governo Vargas instalava a ditadura do Estado Novo, prendendo e torturando seus opositores. Assim ele responde à namorada americana que lhe questionara por que tudo aquilo acontecia sem violência e nem sangue:

Então eu, de olhos semicerrados, acariciando os ombros da rapariga, murmurei com sorriso preguiçoso: 'É muito simples, darling. O brasileiro é avesso à violência'. E passamos a outros assuntos. No entanto era bem

Organon, Porto Alegre, no 47, julho-dezembro, 2009, p.147 - 161 
possível que naquela mesma hora os 'especialistas' da Polícia estivessem aplicando nas suas vítimas seus requintados métodos de tortura. Tu ouviste falar neles... Arrancavam as unhas dos prisioneiros com alicates... esmagavam-lhes os testículos com martelos... aplicavam-lhes pontapés nos rins... Sim, e metiam buchas de mostarda nas vaginas das mulheres dos prisioneiros políticos, ou então as sodomizavam na frente dos maridos... Nós os moços da praia ouvíamos falar nessas brutalidades da Polícia, mas preferíamos achar que tais rumores não passavam duma mórbida ficção, produtos dum sinistro folclore em processo de formação... Recusávamos aceitar essa realidade não-poética. (VERISSSIMO, 1997, p.241)

O posicionamento apolítico e sem nenhum envolvimento social de Floriano vai contra a visão de Edward Said (Op. cit., p.25) de que o intelectual possui um importante papel público na sociedade e por isso "não pode ser reduzido simplesmente a um profissional sem rosto, um membro competente de uma classe, que só quer cuidar de suas coisas e de seus interesses".

Floriano vive em constante divergência com seu pai Rodrigo Cambará, um idealista que traiu seus princípios democráticos em nome de conveniências pessoais e apoiou o regime totalitário de Vargas, e o seu irmão Eduardo que se converteu ao comunismo. Após a queda de Getúlio em 1945, numa discussão política em que o assunto é a eleição do sucessor do ex-presidente, Rodrigo pergunta a Floriano:

- E tu? Não te pergunto em quem vais votar porque és um homem sem compromissos. Nem esquerda nem direita nem centro. Sempre au-dessus de la mêlée, não? Uma posição muito cômoda.

Floriano sente quatro pares de olhos postos nele.

- É curioso - diz, esforçando-se por falar com naturalidade - que tanto o meu pai, homem do Estado Novo, como o meu irmão, marxista e comunista militante, pensem da mesma maneira com relação à minha atitude diante dos problemas políticos e sociais. Para um comunista, a pessoa que 'não se define' é aquela que ainda não entrou para o P.C. Para o meu pai, homem de paixões, as coisas políticas e sociais são pretas ou brancas. Temos de escolher a nossa bandeira e matar ou morrer por ela. Só um intelectual decadente (acha ele) pode perder-se nos matizes, nos meios-tons. Certo ou errado, o importante para o macho é comprometer-se e participar da luta. Ora, eu chamo a isso 'raciocínio glandular'! (VERISSSIMO, 1997, p. 217-218)

O conflito de Floriano com o pai, que contribuiu decisivamente para o agravamento dos seus demais conflitos, vem da Revolução de 1930. Na época, Rodrigo leva-o junto com ele para participar do assalto ao quartel do exército de Santa Fé, apesar do filho ser ainda um garoto. Todos os oficiais rendem-se, com exceção do Tenente Quaresma, que mesmo sendo amigo e freqüentador do sobrado atira em Rodrigo, e este, ferido, pede desesperadamente para que o filho atire em Quaresma, para poder salvá-lo. Mesmo sabendo que a vida do pai depende dele, Floriano não consegue atirar em Quaresma, e a vida de Rodrigo é salva pelos seus companheiros revolucionários. O episódio é uma afronta ao código de honra do gaúcho que deve ser corajoso, macho e peleador, o que faz com que Rodrigo, envergonhado e furioso com o filho, dê-lhe um pontapé no traseiro e o mande de volta à proteção da mãe.

Esse acontecimento, segundo Maria da Glória Bordini (Op. cit., p.237), deixa uma "cicatriz psicológica que o jovem carregará até o fim do romance". Segundo ela, esse trauma, junto com a irremediável alergia pela violência, leva Floriano a defrontar-se com o perigo físico "só para provar a si e - no fundo - ao pai que um intelectual não é necessariamente um covarde". Um desses casos acontece no episódio "Noite de ano bom", em que seu tio Toríbio envolve-se numa briga que o leva à morte. Na tentativa de salvá-lo, Floriano, com uma garrafada põe a nocaute o maior valentão de Santa Fé. Esse acontecimento apaga, aos olhos dos outros, a imagem de covarde deixada na frustrada não participação da Revolução de 30.

Até aqui Floriano Cambará é um intelectual que não conseguiu realizar uma travessia completa do pensamento à ação, não sendo um intelectual totalmente engajado no sentido definido por Sartre. O seu engajamento se dará e se fará completo através da própria literatura, quando decide reencontrar as suas raízes e escrever um romance com enfoque na saga de uma família, tendo como pano de fundo a história do Rio Grande do Sul, pois, segundo o próprio Sartre (2006, p.204), "a literatura é por essência uma tomada de posição" Esse romance que Floriano planeja escrever, descobrimos ao final de $O$ arquipélago, que é a própria historia de $O$ tempo e o vento, pois começa exatamente com as mesmas palavras de $O$ continente (1997), o primeiro romance da trilogia:

Era uma noite fria de lua cheia. As estrelas cintilavam sobre a cidade de Santa Fé, que de tão quieta e deserta parecia um cemitério abandonado. Era tanto o silencio e tão leve o ar, que se alguém aguçasse o ouvido talvez pudesse até escutar o sereno na solidão. (VERISSSIMO, 1997, p.1)

Sobre Floriano Cambará, o próprio Erico (apud. BORDINI, 1997, p.146) afirmou em uma entrevista em 1973, para a jornalista Rosa Freire d'Aguiar, da Revista Manchete, que ele é uma personagem autobiográfica, aquela que mais se parece psicologicamente com o escritor, mas ressalta que não se trata de uma autobiografia estilizada e superficial.

Organon, Porto Alegre, n 47, julho-dezembro, 2009, p.147 - 161 
De certa forma, Erico e sua personagem alter-ego viveram no mesmo período histórico. Um na ficção e o outro na realidade vivenciaram os horrores das Revoluções de 23 e 30 no Rio Grande do Sul e foram contemporâneos da nazi-facismo que criou regimes totalitários na Alemanha, Itália, Espanha e Portugal, e foi o grande pela responsável pela Segunda Guerra Mundial. Tanto um quanto o outro se abstiveram de se filiar às sedutoras ideologias do período, incluindo aí o marxismo-comunismo que era um verdadeiro canto de sereia aos ouvidos dos intelectuais da época. Servimo-nos aqui de uma observação de Maria da Glória Bordini sobre Erico Verissimo, que pode ser extensiva a sua personagem Floriano:

Diante dos problemas internacionais e nacionais, Erico constantemente manteve uma atitude de intelectual independente das tendências ideológico-partidárias que dividiam a arena política. (BORDINI, 2005:12)

No entanto, a partir da década de 60, então em plena Guerra Fria, Erico Verissimo passa a produzir uma literatura mais agressiva e engajada aos problemas sócio-políticos brasileiros e mundiais. Ai é que surge a personagem Pablo Ortega, de $O$ senhor embaixador, um intelectual que se engaja na revolução para libertar a fictícia República de Sacramento do ditador Juventino Carrera. Erico que sempre afirmou ser "contra as revoluções armadas", ressalvando que só aceitava "um tipo de violência: a violência contra a violência" (BORDINI, 1997, p.16), utiliza esse romance, conforme ele próprio declarou (VERISSSIMO, 1976), para estudar a estrutura política, econômica e social das repúblicas latinoamericanas da América Central e do Sul e, principalmente, segundo uma carta do escritor a Daniel Fresnot (1977, p.55), verificar o posicionamento político de um intelectual como Pablo Ortega, que se engaja numa revolução como soldado.

Essa mudança de direção na literatura de Erico foi causada pela evolução intelectual do escritor e pelo desnudamento do imperialismo, que ficou cada vez mais nítido no período da Guerra Fria. Assim, ele passou de romances de cunho social (romances do ciclo de Porto Alegre) e histórico (O tempo e o vento) para um romance nitidamente político, nos termos de Irving Howe (1998, p. 5) que o define como "um romance no qual idéias políticas têm um papel dominante, ou no qual o milieu político é o cenário dominante..." A nosso ver, a trilogia $O$ tempo e o vento realiza a travessia para o romance político, pois começa com um romance histórico, $O$ continente, e passando a ter uma tonalidade política em $O$ retrato, para tornar-se totalmente político em $O$ arquipélago.

Retornando ao romance $O$ senhor embaixador, Daniel Fresnot (Ibid., p.56) acredita que em princípio o escritor condenaria toda e qualquer violência, tanto a dominante (a violência imposta pelo governo de Sacramento) quanto a revolucionaria (a dos rebeldes a quem Pablo se junta). Mas a primeira seria totalmente condenada enquanto que a segunda se apresenta como uma necessidade diante da situação de miséria, tortura, prostituição e tráfico de drogas que vive Sacramento. Assim Pablo Ortega, "aceita a violência como única solução para os males de seu país" (FRESNOT, op. cit., p.56).

Dessa forma, Pablo integra o grupo, conforme definição de Sartre (1994, p. 40), dos verdadeiros intelectuais, aqueles que sabem que a solução nesses casos custará lágrimas e sangue, e assim se engajam nos conflitos de seu tempo com a consciência de estarem ao lado dos oprimidos. Para Edward Said (2005, p. 21), os verdadeiros intelectuais nunca são tão eles mesmos como quando denunciam a corrupção, defendem os fracos, desafiam a autoridade imperfeita ou opressora.

Pablo Ortega, um intelectual que não gosta de ser chamado como tal, é filho de uma tradicional família burguesa de Sacramento e trabalha como secretario da embaixada de seu país em Washington. Vive em contradição consigo mesmo, conforme o modelo de intelectual de Sartre (Op. cit.), angustiado por servir um governo corrupto e totalitário, tendo inclusive, mordomias por parte desse governo, enquanto que a imensa maioria da população sacramentenha vive em estado de miséria, analfabetismo e doença. Segundo Daniel Fresnot (Op. cit., p.36), "a historia de Sacramento parece resumir todos os aspectos negativos da conturbada vida social e política da América Latina” dos anos 50 a 70, opinião compartilhada também por Joaquim Rodrigues Suro (1985, p.209) para quem essa Republica é um "compendio das repúblicas latino-americanas".

Um dos fatos constrangedores que Pablo tem que enfrentar é quando, no seu papel de diplomata, tem que defender um regime que ele abomina:

E o pior... são essas minhas conferências em clubes e universidades em que sou obrigado a contar meiasverdades ou mentiras inteiras sobre o meu país, para manter a ficção de que somos uma democracia. Isso tudo me rebaixa a meus próprios olhos. (VERISSSIMO, 1965, p.8).

Esse trecho, além de confirmar Pablo como um homem-contradição, endossa as palavras de Said (op. cit. p.90) de que o intelectual propriamente dito não é um funcionário inteiramente comprometido com os objetivos políticos de um governo.

Na obra, há também um outro intelectual sacramentenho que vive angustiado com a situação sóciopolítica de seu país. É o professor Leonardo Gris, ex-ministro do governo democrático deposto por

Organon, Porto Alegre, n 47, julho-dezembro, 2009, p.147 - 161 
Carrera, que vive exilado nos Estados Unidos, fazendo conferências em universidades norte-americanas com o intuito de chamar a atenção e lançar luz sobre a verdadeira situação da República de Sacramento. Gris é uma espécie de mestre e conselheiro de Pablo. Numa das conferências realizadas por Gris, assim ele responde a um expectador que lhe pergunta se é comunista:

\begin{abstract}
Não, não sou um comunista, mas um velho liberal até meio romântico, um homem, enfim, que, se decidisse seguir suas inclinações mais profundas, passaria o resto da vida a cultivar o seu jardim no meio de bons amigos, bons livros e boa música, e que, se não faz isso, é porque tem a consciência permanentemente assombrada pela lembrança da miséria de seu povo, e um senso dolorosamente agudo de sua responsabilidade para com esse mesmo povo. (VERISSIMO, 1965, p.220)
\end{abstract}

Leonardo Gris ocupa uma função importante na evolução intelectual e política de Pablo que, por conta de uma chantagem da mãe que utiliza o problema cardíaco de seu pai, hesita em abandonar o serviço diplomático sacramentenho, temendo, com isso, agravar o problema de saúde do pai. No entanto, dois acontecimentos irão propiciar a quebra dessa hesitação: o misterioso desaparecimento de Gris e o desembarque de tropas revolucionárias nos arredores de Soledad del Mar, cidade litorânea da República de Sacramento.

Ao saber do desaparecimento do amigo, com evidências de ter sido seqüestrado e morto a mando do governo da República de Sacramento, Pablo finalmente toma a decisão de se demitir do serviço diplomático de seu país. Abaixo transcrevemos o trecho em que comunica sua decisão ao embaixador Gabriel Heliodoro:

- Comunico-lhe que acabo de telegrafar ao Ministério do Exterior, pedindo minha demissão do serviço diplomático, em caráter irrevogável.

O Embaixador ficou por um instante em silêncio, pensativo, olhando para as próprias mãos. Depois perguntou:

- Por quê?

- Quer mesmo saber?

- É lógico.

Pablo engoliu em seco, cerrou os punhos e disse:

- É porque não posso continuar a servir um governo de assassinos e ladrões.

I...I

- Você pensou bem no que vai fazer? Pensou no seu pai, sua mãe? Pensou também que a noticia de sua demissão só pode agravar a minha situação, aqui em Washington, já tão má depois... depois de todos os outros acontecimentos? (VERISSSIMO, 1965, p.285)

Desse modo, conforme observação de Guilhermino César (apud BORDINI, 1997, p.58), Pablo, num lance de crua sinceridade, joga pela janela fora uma situação social invejável, sacrificando tudo para ficar bem consigo mesmo. Essa atitude enquadra-se na análise que Edward Said (2005, p.23) faz da definição de intelectual de Julien Benda, conceituando-o como "alguém capaz de falar a verdade ao poder, um indivíduo ríspido, eloqüente, fantasticamente corajoso e revoltado, para quem nenhum poder do mundo é demasiado grande e imponente para ser criticado e questionado de forma incisiva."

Após seu desligamento do serviço diplomático e ao tomar conhecimento da eclosão do movimento revolucionário em Sacramento, Pablo não teve dúvida que seu lugar era ao lado do povo e dos revolucionários.

Quando Pablo Ortega leu nos jornais a notícia do primeiro desembarque de tropas rebeldes nos arredores de Soledad del Mar, compreendeu que uma nova porta se lhe abria e que seu destino agora estava claro. Não lhe restava outra alternativa senão juntar-se às forças de Miguel Barrios. Várias imagens e vozes em seus pensamentos apontavam-lhe o caminho da Revolução.

Decidiu não pensar mais no estado do coração do pai, e começou a preparar-se para partir. Estudou os caminhos mais seguros para chegar à Serra. E todos aqueles preparativos - desfazer o contrato de aluguel do apartamento, pagar as contas, rasgar e queimar papéis - produziam-lhe um alvoroço de menino em véspera dum longo feriado com possibilidades de aventura. Suas dores de cabeça desapareceram e ele ficou a ponto de se reconciliar-se com o sujeito que todas as amanhãs lhe aparecia no espelho, à hora de barbear-se. (VERISSIMO, 1965, p.301)

Assim Pablo soluciona o seu problema existencial, metaforizado na constante dor de cabeça que lhe perseguia, apazigua a sua consciência e vai se juntar aos revolucionários. Para Daniel Fresnot (Op. cit., p.38), toda a ação dele foi a procura realista de agir em função de sua consciência e esse seu engajamento extremo e total foi fruto do conhecimento que possuía da realidade de seu país e da clara consciência de que era impossível permanecer inativo diante dessa realidade. 
Os revolucionários entram vitoriosos em Cerro Hermoso, capital de Sacramento, que nessa altura, com a fuga do ditador Juventino Carrera para a República Dominicana, estava sendo defendida pelo embaixador Gabriel Heliodoro, que é preso e levado a julgamento pelo Tribunal Revolucionário, acusado de ter cometido diversos crimes contra a nação. No entanto, após juntar-se aos revolucionários, começam a surgir divergências entre Pablo e Roberto Valencia, o braço direito de Miguel Barrios, o chefe da revolução. Interrogado pelo seu amigo William B. Godkin, um jornalista norte-americano especialista em política latino-americana, sobre o que havia entre ele e Valencia, Pablo lhe responde:

- Ora, sendo eu um intelectual, filho de latifundiário e ainda por cima um ex-diplomata, desde o primeiro dia fiquei sob a suspeita de Valencia. E sua má vontade para comigo revela-se nas menores coisas. (VERISSIMO, 1965, p.327)

Valência acusa-o de ser um intelectual pequeno burguês que não estava preparado nem física nem psicologicamente para a ação revolucionária:

Ele me acusou de ser um indeciso, um intelectual que procura o impossível meio-termo, obcecado por um sentimento de culpa mais mitológico que real. 'Afinal de contas (perguntou ele) você quer libertar seu povo da tirania e da miséria ou quer apenas apaziguar sua consciência de individuo?' Fiquei furioso porque o diabo do homem havia tocado no nervo vivo do meu problema. Procurou me convencer que o meio-termo não leva a parte nenhuma, pois a Historia tem provado que só a violência pode partejar as grandes mudanças sociais. (Ibid., p.331)

Questionado por Godkin sobre o que pretendia fazer, Pablo responde ao amigo que iria continuar, iria até o fim. Seria um espinho no flanco de Valencia, mas sempre fiel à revolução. Não faria como muitos intelectuais que, em situações como aquela, recuam, ressentidos e começam uma contra-revolução.

Como se não bastasse a desconfiança de Valencia, Pablo também enfrenta problemas com a mãe, que o acusa de ser responsável pela morte do pai, ocorrida logo no inicio da revolução quando aderiu aos revolucionários. Ele comenta com Godkin como a estação de rádio oficial noticiou o assunto.

Fizeram um grande ruído em torno da morte de Don Dionísio, dum colapso cardíaco. Disseram claramente que foi vitimado pelo desgosto de me ver com a 'canalha revolucionária'. Entrevistaram minha mãe, fizeram a velha gravar uma entrevista na qual confirmava a causa da morte do marido, chamava-me de assassino e declarava que não me queria ver nunca mais... (Ibid.:323)

Dessa forma, Pablo é considerado traidor pela sua própria família e pela classe social a qual pertence, e também é tratado com desdém e desconfiança por Valencia, o cérebro da revolução sacramentenha. Aqui é pertinente invocarmos novamente Jean-Paul Sartre para comentar essa situação vivida pelo intelectual:

...ele não tem mandato de ninguém: suspeito às classes trabalhadoras, traidor para as classes dominantes, recusando sua classe sem jamais poder se livrar totalmente dela, até nos partidos populares ele reencontra, modificadas e aprofundadas, suas contradições; até nesses partidos, se neles entrar, ele se sente ao mesmo tempo solidário e excluído, já que ali continua em conflito latente com o poder político: inassimilável em todos os lugares. Sua própria classe não o quer, assim como ele não a quer, mas nenhuma outra classe se abre para acolhê-lo. (SARTRE, 1994, p.51)

Instalado o governo revolucionário, a situação entre Pablo e Valencia torna-se ainda mais tensa em razão do primeiro ter solicitado a Barrios para ser o advogado de defesa de Gabriel Heliodoro, enquanto que o segundo seria o promotor de acusação. Barrios dá sua permissão, mas diz-se surpreendido pelo gesto de Pablo e alerta que isto pode ser-lhe prejudicial, e que a posição dele dentro do movimento pode ficar consideravelmente enfraquecida e que ninguém compreenderá esta atitude.

Como era esperado, Gabriel Heliodoro foi condenado à morte por fuzilamento e Pablo, mesmo desiludido com os rumos que a revolução tomava, podendo transformar-se numa nova ditadura, percebe "que a luta para ele não terminara com a tomada do poder" (FRESNOT, 1977, p.33), e que num futuro próximo ele poderia ser obrigado a procurar asilo político em outro país, tornando-se uma persona non grata ao novo governo sacramentenho.

4 Considerações finais

Organon, Porto Alegre, n 47, julho-dezembro, 2009, p.147 - 161 
A nosso ver Pablo Ortega é uma continuação de Floriano Cambará. Ambos são intelectuais humanistas, têm horror à violência, têm suas origens nas classes abastadas de seus países e prezam pela liberdade de si mesmos e de todo ser humano. Nesse sentido, pelas suas preocupações políticas e sociais, eles se encaixam perfeitamente na definição de intelectual tanto de Jean-Paul Sartre quanto de Edward Said: são homens-contradição, são outsiders. Por isso vivem no entre-lugar (lembrando Silviano Santiago) entre dois pólos opostos, não aceitam a vida como se tudo fosse preto ou branco, conforme afirmação do próprio Erico sobre a definição do homem liberal. Assim são homens- cinza, homens-talvez entre o sim e o não.

O que difere um do outro é o "passo a mais" que Pablo Ortega dá ao se engajar na revolução sacramentenha. Mas isso, acreditamos, seja consequiência do tempo histórico diferente em que essas duas personagens ganham vida pelas mãos de Erico. Floriano viveu no terrível período da Segunda Guerra Mundial, onde apesar do caos havia uma certa esperança no pós-guerra, havia ainda a utopia da nãoviolência em razão da própria violência desencadeada no conflito. Já Pablo Ortega viveu no contexto histórico-político da Revolução Cubana e da Guerra Fria, um tempo que era necessário tomar posição e não assistir aos acontecimentos pelos jornais, sentado à sombra de uma árvore, como afirmou o próprio Erico Verissimo na capa de O prisioneiro (1970). Assim Pablo vai para Sacramento e se engaja na revolução que busca livrar o país da opressão social e política. Pensamos que, se Floriano Cambará vivesse ficticiamente no mesmo período de Pablo, fatalmente ele também se engajaria, daria o seu "passo a mais".

Dessa forma, Pablo representa uma evolução do pensamento do escritor sobre a questão do engajamento ou não do intelectual, e por isso, para análisá-lo, é necessário passar primeiro por Floriano Cambará. Com Pablo surge, na obra de Erico, a figura do homem de pensamento que se torna um homem de ação, quando a necessidade histórico-politica exige.

Bibliografia

BORDINI, Maria da Glória. A liberdade de escrever: entrevistas sobre literatura e política. Porto Alegre: Ed. UFRGS, EDIPUCRS, 1997.

. Criação literária em Erico Verissimo. Porto Alegre: L\&PM, 1995.

.Erico Verissimo, um intelectual independente. Revista Ciências e Letras, Porto Alegre, n. 38, jul./dez. 2005, p. 8-13.

CANDIDO, Antonio. Erico Verissimo de trinta a setenta. In CHAVES, Flávio Loureiro (org.). $O$ contador de histórias: 40 anos de vida literária de Erico Verissimo. Porto Alegre: Globo, 1972, p. 40-51. CESAR, Guilhermino. O romance social de Erico Verissimo. In CHAVES, Flávio Loureiro (org.). $\boldsymbol{O}$ contador de histórias: 40 anos de vida literária de Erico Verissimo. Porto Alegre: Globo, 1972, p. 52-70. CHAVES, Flávio Loureiro. Erico Verissimo e o mundo das personagens. In CHAVES, Flávio Loureiro (Org.). O contador de histórias: 40 anos de vida literária de Erico Verissimo. Porto Alegre: Globo, 1972, p.71-85.

FRESNOT, Daniel. O pensamento político de Erico Verissimo. Rio de Janeiro: Edições do Graal, 1977.

FUSINATO, Socrates. A imprevisibilidade da escrita a instigar a atitude crítica do intelectual. In. Congresso internacional abralic, 9, 2004. Anais.... Porto Alegre, 2004.

GRAMSCI, Antonio. Os intelectuais e a organização da cultura. 4 ed. Rio de Janeiro: Civilização Brasileira, 1982.

HOWE, Irving. A política e o romance. Trad. Margarida Goldsztsjn. São Paulo: Perspectiva, 1998.

SAID, Edward. Representações do intelectual: As Conferências Reith de 1993. Trad. Milton Hatoum. São Paulo: Companhia das Letras, 2005.

SARTRE, Jean-Paul. Em defesa dos intelectuais. Trad. Sérgio Góes de Paula. São Paulo: Ática, 1994.

Que é a literatura. 3 ed. Trad. Carlos Felipe Moisés. São Paulo: Ática, 2006.

SCLIAR, Moacyr. A consciência de uma nação. In.: Caderno Mais, Folha de S. Paulo. 09/06/2006.

SURO, Joaquim Rodriguez. Erico Verissimo: história e literatura. Porto Alegre: D.C. Luzzatto Editores, 1985.

VERISSIMO, Erico. O arquipélago. 34 ed. São Paulo: Globo, 1997.

. O continente. 34 ed. São Paulo: Globo, 1997.

O retrato. 34 ed. São Paulo: Globo, 1997.

O senhor embaixador. Porto Alegre: Globo, 1965.

O prisioneiro. Porto Alegre: Globo, 1970.

Organon, Porto Alegre, n 47, julho-dezembro, 2009, p.147 - 161 

1976.

Solo de clarineta: memórias. 2 volume. CHAVES, Flávio Loureiro (org.) Porto Alegre: Globo, 